(C) 2020 IEEE

The 46th Annual Conference of the IEEE Industrial Electronics Society - IECON 2020

Flexibility Enhancements in Pumped Hydro Storage Power Plants through Variable Speed Drives

P. Bontemps, N. Hugo, and D. Dujic

This material is posted here with permission of the IEEE. Such permission of the IEEE does not in any way imply IEEE endorsement of any of EPFL's products or services. Internal or personal use of this material is permitted. However, permission to reprint / republish this material for advertising or promotional purposes or for creating new collective works for resale or redistribution must be obtained from the IEEE by writing to pubs-permissions@ieee. org. By choosing to view this document, you agree to all provisions of the copyright laws protecting it. 


\section{Flexibility Enhancements in Pumped Hydro Storage Power Plants through Variable Speed Drives}

\author{
Philippe Bontemps \\ Power Electronics Laboratory \\ EPFL \\ CH-1015 Lausanne, Switzerland \\ philippe.bontemps@epfl.ch
}

\author{
Nicolas Hugo \\ Asset Management Support \\ Alpiq SA \\ CH-1001 Lausanne, Switzerland \\ nicolas.hugo@alpiq.com
}

\author{
Drazen Dujic \\ Power Electronics Laboratory \\ EPFL \\ CH-1015 Lausanne, Switzerland \\ drazen.dujic@epfl.ch
}

\begin{abstract}
The rapidly increasing number of renewable energy installation that are not able to contribute to grid stabilisation, together with the shut down of thermal power plants requires additional measures to ensure future grid stability. Pumped hydro storage power plants conventionally operating at fixed speed can contribute to grid stability and flexibility by being equipped with a variable speed drive. This paper analyses the scenario where a single unit of an existing power plant is retrofitted into a variable speed drive. The benefits of such a retrofit on the unit itself, as well as the impact on the operation of the existing fixed speed units operating is analyzed and simulations of various scenarios to demonstrate those benefits are developed in this paper.

Index Terms-Variable speed drives, hydro applications, power electronics
\end{abstract}

\section{INTRODUCTION}

The use of variable speed drives in pumped hydro storage power plants (PHSP) having started in 1990 in Japan, is becoming increasingly more popular all around the world. Being a well established technology, the advantages of variable speed drives in PHSP are well known and presented in various papers [1]-[4]. With the increased integration of renewable energy sources such as PV which are highly intermittent and not providing any inertia, it is important to maintain stability in the grid. The developments in large scale energy storage systems such as batteries, leading to lower prices and ability to respond instantly to any power requirement from the grid, represents only one of the multiple technologies that might replace some off the services offered by conventional power plants. Facing these developments, PHSP need to mitigate to variable speed to stay competitive and remain a relevant player on the power market. Conventional PHSP operating at a fixed speed cannot offer flexibility as they can only operate at a fixed operating point defined by the ratings of the installed equipment. The use of variable speed drives adds flexibility and contributes to grid stability by absorbing or injecting variable power to the grid as well as fast response, typical for power electronics technologies.

Two main configurations are used to operate a PHSP at variable speed, mainly the doubly fed induction machine (DFIM), seen on Fig. 1a, and the converter fed synchronous machine (CFSM), seen on Fig. 1b, each of them coming with their own benefits and drawbacks. The main advantage of the DFIM, which is also the reason for it's popularity

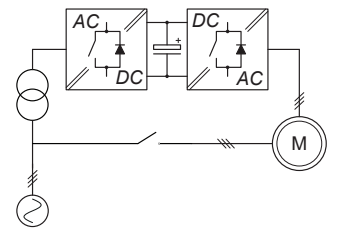

(a)

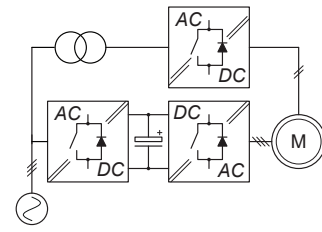

(b)
Fig. 1. Simplified representation of two typical variable speed drive configurations used in PHSP, (a) DFIM and (b) CFSM.

compared to CFSM is the size of the frequency converter. As the converter is installed on the rotor, it is rated at only the slip power, typically between 10 to $30 \%$, of the rated power of the electric machine. Drawbacks of this setup are coming from the fact that the stator of the DFIM is directly connected to the grid, creating issues during low-voltage ride-through, requiring additional devices for synchronisation and safety measures as well as a phase reversal equipment to enable a change in the direction of rotation to operate in both turbine and pump mode. Additionally, the low power rating of the converter limits the start-up torque, leading to higher start-up times in pumping mode, requiring dewatering of the pump.

With the converter fed synchronous machine (CFSM), most of the drawbacks of the DFIM are eliminated as the frequency converter decouples the machine from the grid, as seen on Fig 1b. While with this setup no additional electrical constraints are added to the system, the main drawback however is the power ratings of the frequency converter that needs to match the power ratings of the machine, limiting this configuration to PHSP with lower power levels. The biggest currently operating PHSP using CFSM is Grimsel 2 in Switzerland, with a total converter power of $100 \mathrm{MW}$ [5]. The converter is based on a three-level active neutral pointed clamped topology and is bypassed during generation due to specific operational constraints of the particular installation. In pumping mode, the power regulation is in the range from $60 \mathrm{MW}$ to $90 \mathrm{MW}$, which is restricted, considering full power ratings, due to safe operating limits of the hydraulic part of the system.

This paper explores the benefits of the integration of a full size frequency converter on a single unit in a conventional PHSP with multiple units. The specific case of the Z'Mutt power plant station in Switzerland, is used to demonstrate the expected improvements for an existing power plant. 


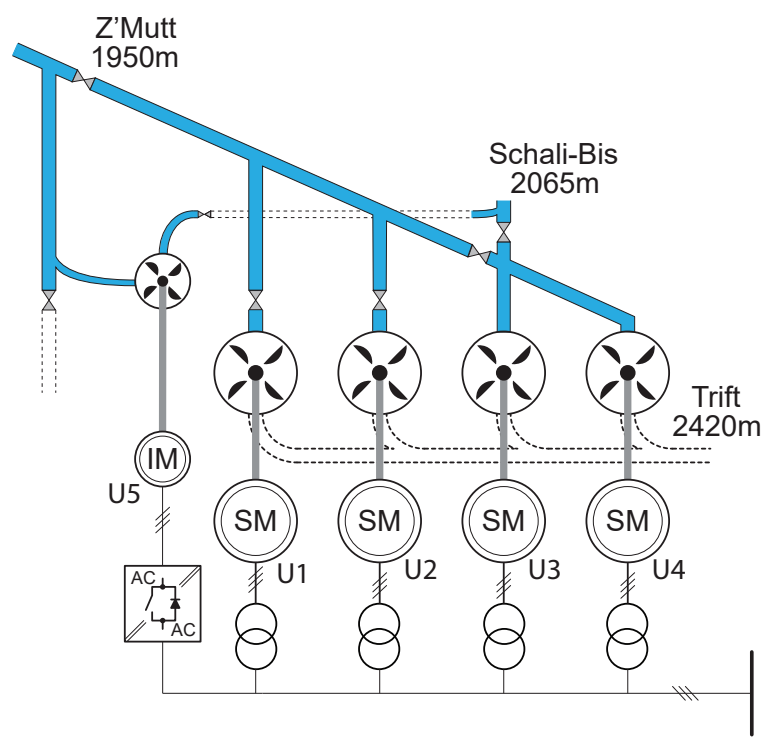

Fig. 2. Layout of the Z'Mutt power plant station with five electric motors, four synchronous machine units (U1 to U4) producing a total power of $88 \mathrm{MW}$, and one induction machine bypass unit (U5) with $3 \mathrm{MW}$ ratings

\section{Z'MUTT POWER PLANT STATION}

Z'Mutt is a pumping station with a total installed power of $88 \mathrm{MW}$ and can discharge up to $18.2 \frac{\mathrm{m}^{3}}{\mathrm{~s}}$ of water. Fig. 2 shows a simplified representation of the power plant station layout with a total of five units (Us) with three different power levels:

- Two pumps discharging $5.5 \frac{\mathrm{m}^{3}}{\mathrm{~s}}$ against $470 \mathrm{~m}$ head, with a $30 \mathrm{MW}$ synchronous machine each (U1 and U2)

- Two pumps discharging $3.6 \frac{\mathrm{m}^{3}}{\mathrm{~s}}$ against $365 \mathrm{~m}$ head, with a $14 \mathrm{MW}$ synchronous machine each (U3 and U4)

- One bypass pump discharging $2 \frac{\mathrm{m}^{3}}{\mathrm{~s}}$ against $90-130 \mathrm{~m}$ head, with a $3 \mathrm{MW}$ induction machine (U5)

This paper focuses on the benefits of installing a frequency converter on either of the $30 \mathrm{MW}$ synchronous motors, labelled U1 and U2 on Fig. 2, which are only used for pumping in summer season. As of today, the four main units of the power plant station don't have any flow control device other than the pump discharge valve (PDV). This PDV is either open or closed and does not allow any flow regulation, which means that for the fixed operating speed, the active power requirement from the grid is defined only by the water level of the upper and lower reservoirs. A total of three reservoirs are connected to the power plant station. The highest one, Trift, varying between $2424 \mathrm{~m}$ and $2419 \mathrm{~m}$, the middle reservoir, Schali-Bis, varying between $2066 \mathrm{~m}$ and $2059 \mathrm{~m}$ and the compensating basin, Z'Mutt, varying between $1972 \mathrm{~m}$ and $1930 \mathrm{~m}$. The currently used start-up procedure of the synchronous motor consists of an asynchronous start where the rotor is short circuited until synchronous speed is nearly achieved, then the excitation on the rotor is applied and the motor synchronises with the grid. Installing a full size frequency converter on one of this units enables smooth start-ups as well as power regulation in pumping mode.
TABLE I

NOMINAL PARAMETERS OF UNIT 1

\begin{tabular}{lc}
\hline Parameter & Value \\
\hline \hline Apparent Power & $31.7 \mathrm{MVA}$ \\
Voltage & $10 \mathrm{kV}$ \\
Current & $1.83 \mathrm{kA}$ \\
Torque & $180.4 \mathrm{kNm}$ \\
Field Current & $341.71 \mathrm{~A}$ \\
Pole pairs & 2 \\
Frequency & $50 \mathrm{~Hz}$ \\
Machine inertia & $3300 \mathrm{kgm}^{2}$ \\
Pump inertia & $3600 \mathrm{kgm}^{2}$ \\
\hline
\end{tabular}

\section{CONVENTIONAL PHSP OPERATION}

The start-up process of conventional fixed speed PHSP can be done either with an auxiliary turbine or via a process called asynchronous start-up. Being one of the simplest and fastest methods of starting the synchronous motor, the asynchronous start creates high inrush currents that stresses the winding of the motor and may result in a voltage sag on the grid. In order to avoid this voltage sag, or insulation damage to the machine, the inrush current can be limited using different methods [6]. A three phase reactor or an autotransformer, both fulfilling the same duty of limiting the inrush current and being bypassed once the inrush current has been limited, can be added to the system to limit the stress on the machine. However, limiting the stator current comes at the cost of having limited torque available during start-up, leading to an increase in start-up time. In Z'Mutt, U1 and U2 are both started by a direct connection to the grid without any current limiting device. During the initial part of the start-up, the stator is directly connected to the grid and the rotor is short circuited with an additional $1.6 \Omega$ resistance. Operating as asynchronous machine, the produced electromagnetic torque is defined by the following equation [7]:

$$
T_{e m}=\frac{\frac{3}{2} p U_{s}^{2} \frac{R_{r}}{s}}{\omega_{s}\left(\left(R_{s}+\frac{R_{r}}{s}\right)^{2}+\omega_{s}^{2}\left(L_{\gamma s}+L_{\gamma r}\right)^{2}\right)}
$$

Where $U_{s}$ defines the rms voltage on the stator, $\mathrm{p}$ the number of pole pairs and $L_{\gamma s}$ and $L_{\gamma r}$ are the stator and rotor leakage inductances. This equation can be simplified for the two regions of interest, namely the starting torque (slip (s) close to 1$)$, assuming that $\left(R_{s}+R_{r}\right) \ll \omega_{s}\left(L_{\gamma s}+L_{\gamma r}\right)$ and at pull-in torque (slip close to 0 ), assuming that $\frac{R_{r}}{s} \gg$ $\omega_{s}\left(L_{\gamma s}+L_{\gamma r}\right) \gg R_{s}$ giving the two simplified expressions:

$$
\begin{array}{ll}
T_{e m} \approx \frac{\frac{3}{2} p U_{s}^{2} R_{r}}{\omega_{s}^{3}\left(L_{\gamma s}+L_{\gamma r}\right)^{2}} & \text { For s close to } 1 \\
T_{e m} \approx \frac{\frac{3}{2} p U_{s}^{2} s}{\omega_{s} R_{r}} & \text { For s close to } 0
\end{array}
$$

Increasing the start-up torque by adding a external resistance on the rotor, comes with the trade-off of a reduced final torque near synchronous speed.

Simulations of the current start-up procedure at Z'Mutt are shown in Fig. 3 - 5. Fig. 3 shows the variation of the 


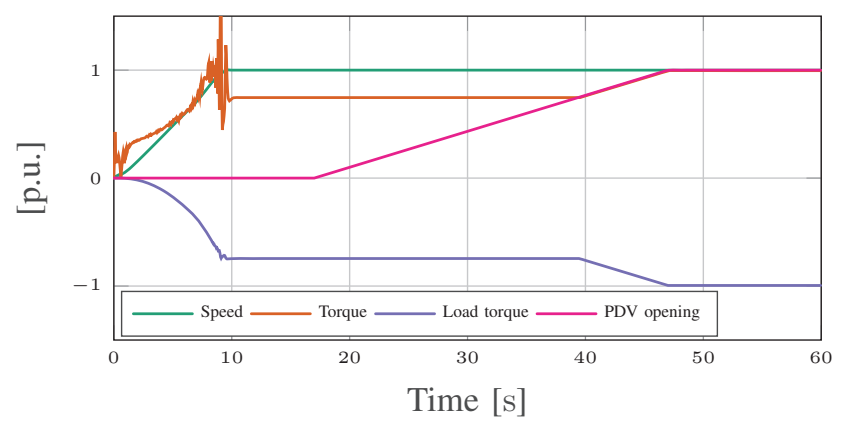

Fig. 3. Simulation results showing the normalized variation of the speed, torque, head and PDV opening from standstill to nominal pumping operating point

measurements during the start-up procedure without full size frequency converter (FSFC), directly connecting U1 to the grid. The maximum torque produced by the machine is only marginally bigger than the load torque created by the head, for this reason the pump discharge valve must remain closed during the start-up of the machine. This process of speeding up the machine to nominal speed takes currently about 10 seconds. After the nominal speed of the machine is achieved, synchronisation to the grid occurs before opening the PDV. It takes currently about 8 seconds after the nominal speed of the machine has been achieved until the start of the opening of the PDV. The opening process of the PDV takes another 30 seconds after which the full torque is delivered by the pump and the nominal discharge rate is achieved. After the start-up process, the pump operates at a constant discharge and head, thus constant power reference absorbed from the grid. The whole starting process, before the pump operates at nominal speed and at full discharge, takes a total of approximately 48 seconds.

Fig. 4, shows the speed up process of the U1 by directly connecting the machine to the grid. As previously developed in (1), the asynchronous torque at low speeds can be increased with an additional resistance on the rotor winding, in the case of Z'Mutt an additional external resistance of $1.6 \Omega$ is added to the rotor circuit. Even with the additional resistance, the torque produced by the machine throughout the whole speed up process is far below the nominal torque of the synchronous machine, increasing the time to reach nominal speed. During the start-up process with a direct connection to the grid, a high inrush current is measured at the stator of the machine, as shown in Fig. 5. This current rises up to four times the nominal current of the machine, creating a voltage drop on the line connected to the stator.

The installation of a FSFC would allow to shorten the speed up time of the machine significantly, as full torque can be applied at zero speed. As mentioned in the introduction, the largest installed FSFC in a PHSP is in Grimsel 2 with a total power of $100 \mathrm{MW}$. Even if this power plant station operates in both, pumping and turbine mode, the converter is bypassed when operating in turbine mode allowing variable speed only in pumping mode. In the case of Z'Mutt, the unit of interest

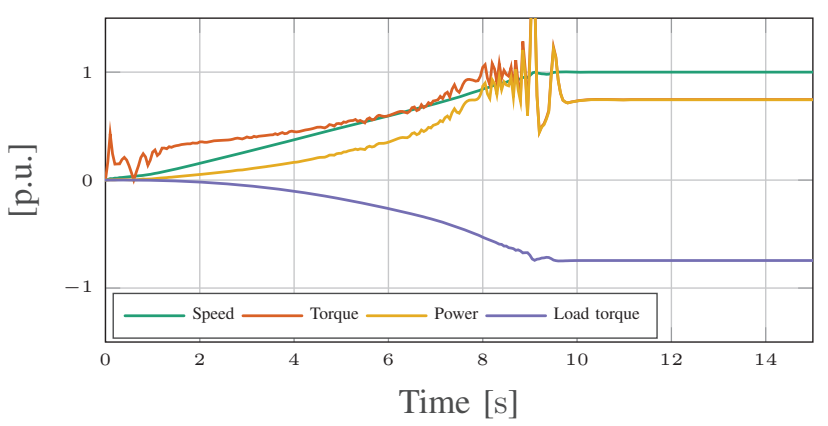

Fig. 4. Simulation results showing the normalized variation of speed, torque, power and load torque during the speed up of the electric motor with a direct connection to the grid.

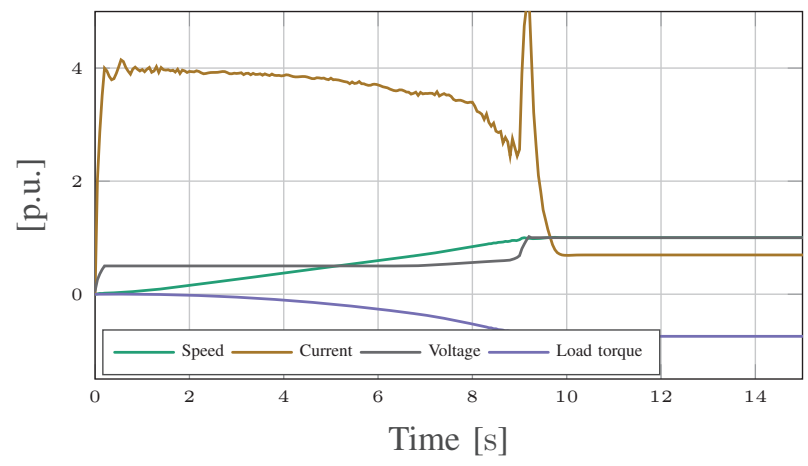

Fig. 5. Simulation results showing the normalized variation of speed, stator current, stator voltage and load torque during the speed up of the electric motor with a direct connection to the grid.

is only operated in pumping mode thus allowing the converter to be constantly connected to the generator. As the U1 power ratings corresponds to one third of the power from Grimsel 2 , the converter technology for such power levels is already existing on the market, and can be based either on conventional multilevel topologies or modular multilevel converter [8], [9].

\section{Modelling of a PHSP with a CFSM}

Connecting a frequency converter to the synchronous machine eliminates the need of any additional equipment during the start-up as the variable output frequency allows for a soft start without inrush current that would exceed the ratings of the machine. Once operating at nominal speed, conventional PHSP cannot regulate the power consumption with a single unit. For ternary units, creating a hydraulic short circuit creates the possibility to dynamically change the power consumption from the grid without the addition of a FSFC. In this scenario, the waterways of the pump and the turbine are directly connected together, and by varying the water flow from the upper reservoir to the turbine, the power consumption of the pump can be regulated.

With a frequency converter however, the change in speed is possible without hydraulic short circuit creating a more dynamic response to a power reference change. Small variation in the net head can be monitored, and the speed of the turbine can be modified to always operate at the best efficiency point. 


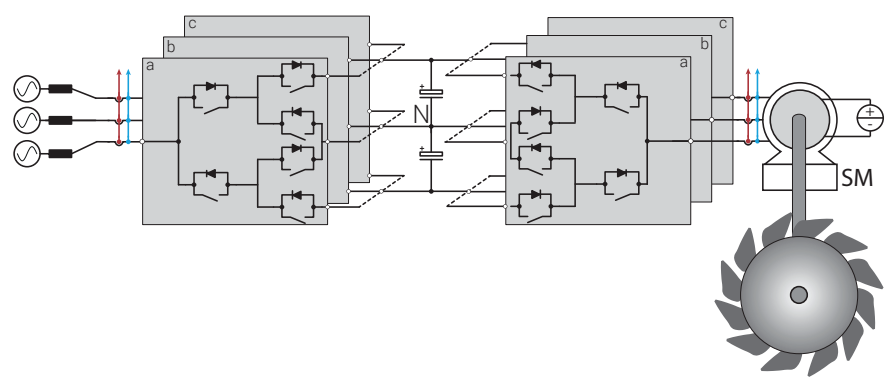

Fig. 6. Simulation model using a three level active neutral point clamped converter topology connected to a synchronous machine with additional inertia to simulate the pump.

Additionally, a reduction in wear of various elements of the pump and of the machine can be achieved, as the pump is operated partly below maximum speed. Retrofitting current fixed speed PHSP with a frequency converter does not only give the possibility of a dynamic change in the power consumption, but has as well the advantage of decoupling the machine from the grid. This decoupling leads to better behaviour during grid faults, as the machine will not directly be affected, but only the active front end (AFE) of the converter, which is controlled to comply with the grid codes during faults.

Some points, regarding the machine as well as the pump, need to be taken into account before installing a frequency converter on a fixed speed machine. As the pump will not be operating at the fixed speed defined during the design phase, the operational speed which can be below this defined speed might lead to some structural resonances that could lead to vibrations, creating additional noise or even damaging the installation. A speed range is to be defined by taking into account the hydraulic restrictions as well as the electrical ratings of the installation. On the machine side, the switching of the frequency converter creates squared waveforms with a high $\frac{\delta V}{\delta t}$ that might lead to premature insulation damages, unless carefully assessed against available machine design.

A representation of the model used for the simulations is seen on Fig. 6. The topology of the frequency converter is a back-to-back three level active neutral point clamped one (3LANPC). The choice of a 3L-ANPC is based on the fact that this topology is equivalent to the one of the ABB PCS8000 frequency converter which is deployed in the PHSP Grimsel 2, rated at $100 \mathrm{MW}$ [10]. Having a modular converter structure, the PCS8000 can easily be scaled to the $30 \mathrm{MW}$ application needed for Z'Mutt. Details about the converter can be found in Table II. The control structure of the converter, shown on Fig 7 and Fig 8, is very established and known. The control structure of the grid side converter is responsible of controlling the DC-link voltage and in case of a grid fault acting in a way to comply with the grid code regulations. For the control of the machine side converter, a rather classical vector control is considered to operate the machine at a given speed and absorb a given power reference from the grid.

To model the non electric parts consisting of the turbine and the influence of the water on the turbine, an equivalent
TABLE II

Medium Voltage POWER CONVERTER PCS 8000

\begin{tabular}{lc}
\hline \multicolumn{2}{c}{ PCS8000 Data } \\
\hline \hline Power range & $15-100 \mathrm{MVA}$ \\
Grid voltage & $6-220 \mathrm{kV}$ \\
Machine voltage & $6 \mathrm{kV}$ \\
Input frequency & 50 or $60 \mathrm{~Hz}$ \\
Output frequency & $0-66 \mathrm{~Hz}$ \\
Cooling & Closed loop water cooling \\
Technology & MV IGCT semiconductors \\
\hline
\end{tabular}

influence of those parameters is created. For the turbine, this consists of a simple inertia that is added to the shaft, and with the assumption that there is no vibration on the shaft created by the turbine, this is a valid model. The water acting on the turbine, can be modeled by a simple load torque applied to the shaft. This load torque, simulating the pressure of the water on the turbine, can be determined by the following set of equations:

$$
\begin{gathered}
P_{\text {shaft }}=\gamma Q g H=25.26 \mathrm{MW} \\
T_{\text {shaft }}=\frac{P_{\text {shaft }}}{\omega_{\text {shaft }}}=161.44 \mathrm{kNm}
\end{gathered}
$$

Where $\gamma$ is the water specific density $\left(1000 \frac{\mathrm{kg}}{\mathrm{m}^{3}}\right), \mathrm{g}$ is the gravitational acceleration $\left(9.81 \frac{\mathrm{m}}{\mathrm{s}^{2}}\right), Q$ is the flow rate $\left(5.5 \frac{\mathrm{m}^{3}}{\mathrm{~s}}\right)$, $H$ is the turbine head $(470 \mathrm{~m})$ and $\omega_{\text {shaft }}$ the speed of the shaft $\left(157.08 \frac{\mathrm{rad}}{\mathrm{s}}\right)$.

With the assumption that the level of the reservoirs remains unchanged, this torque remains constant throughout the startup process of the pump. If the power reference changes during operation of the pump, the speed needs to be adapted to keep the produced torque at the shaft constant. The discharge of the pump following a change of speed varies linearly:

$$
Q_{\text {new }}=\Omega_{\text {new }} \frac{Q_{\text {old }}}{\Omega_{\text {old }}}
$$

As the water level in a reservoir does not remain constant throughout an entire pumping season, the variation of the

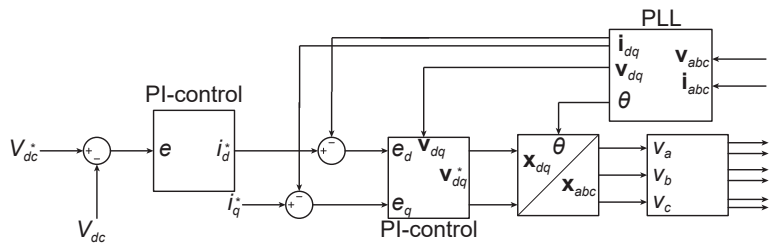

Fig. 7. Simplified grid side converter control structure.

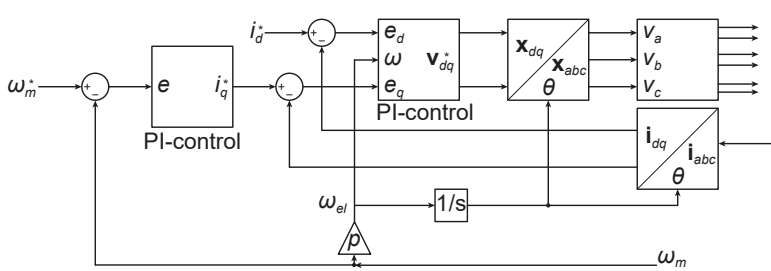

Fig. 8. Simplified motor side converter control structure. 
load torque following a change in the water level needs to be defined. For Z'Mutt the maximum variation for the upper and the lower reservoir is $5.09 \mathrm{~m}$ and $41.6 \mathrm{~m}$ respectively which leads to a maximum and minimum head of $494.35 \mathrm{~m}$ and $447.66 \mathrm{~m}$, giving a maximum load torque span of:

$$
T_{\text {shaft }} \in\left[\begin{array}{ll}
153.77 & 169.80
\end{array}\right] \mathrm{kNm}
$$

During the start-up phase, the PDV remains closed to allow faster starting times. As the pump is not dewatered, the torque seen on the shaft of the pump varies with the square of the speed, as defined in (8).

$$
T_{\text {shaft }}=k_{F_{W}} \Omega_{m}^{2}
$$

Where $k_{F_{W}}$ is the friction coefficient of the pump in the water turning with closed PDV. This coefficient will be calculated using start-up measurements of the speed and torque from U1.

\section{Simulation Results}

Start-up procedure: From the data of Fig. 3, the friction coefficient with closed PDV can be determined, and this friction is modelled as a load torque that varies proportionally to the square of the rotational speed of the turbine, as expressed in (8), resulting in $k_{F_{W}}=0.06$. With the frequency converter, full torque can be achieved at zero speed without exceeding the nominal ratings of the machine, thus not damaging the insulation while having a fast start-up. Installing a FSFC, will have an impact on time needed to achieve nominal speed of the machine, but the opening time of the PDV remains the same. As there is no need to achieve nominal speed to synchronize, the PDV can start opening even if the machine is not at nominal speed, which can further accelerate the starting process. The decrease in start-up time due to the installation of a FSFC on the machine, can be seen on Fig 9. Nominal speed of the machine is reached within 5 seconds, due to the full torque applied from standstill, and as there is no need for synchronisation, adding the 30 seconds of PDV opening the whole start-up process takes under 35 seconds representing a reduction of $27 \%$ compared to the direct connection to the grid. Fig. 10 shows that during the whole speed up of the machine, the stator current never exceeds the nominal current by more than $20 \%$.

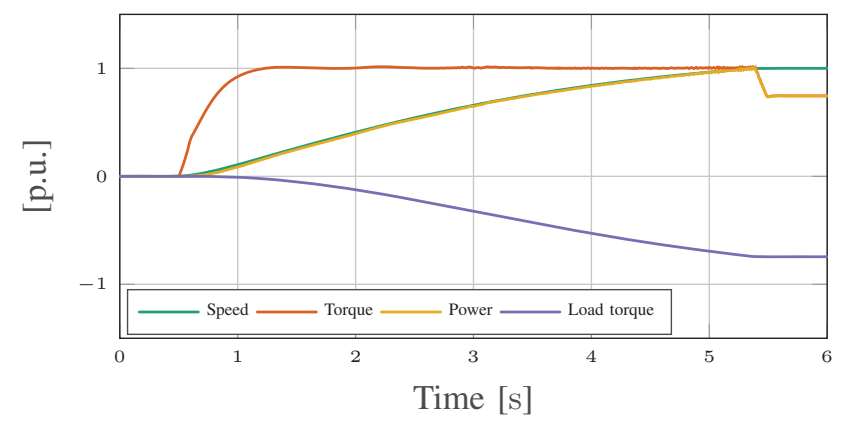

Fig. 9. Simulation results showing the normalized variation of speed, torque, power and load torque during the speed up of the electric motor with a FSFC

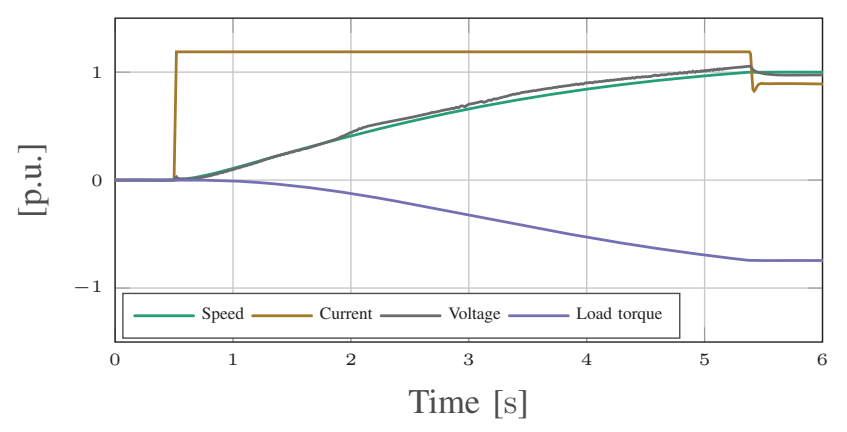

Fig. 10. Simulation results showing the normalized variation of speed, stator current, stator voltage and load torque during the speed up of the electric motor with a FSFC

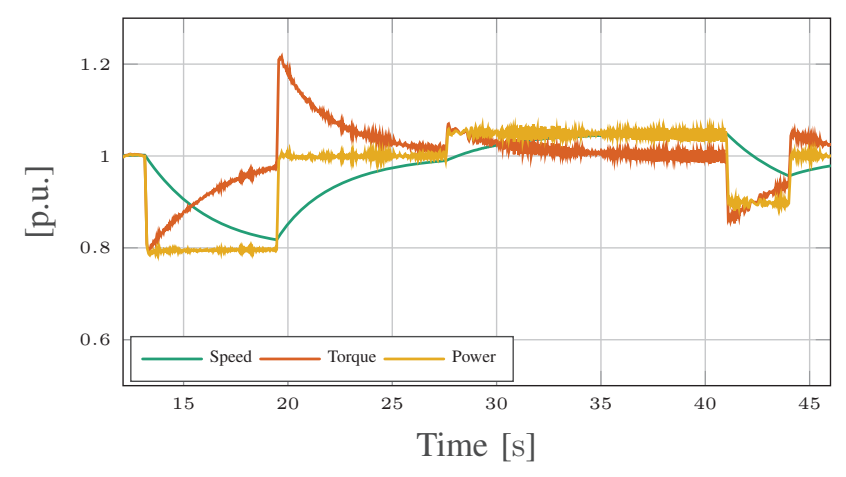

Fig. 11. Pumping simulation results showing the normalized variation of speed, torque, power and load torque with a FSFC.

Pumping operation at variable speed: Once the PDVs are opened and water is being pumped, the lack of a flow control device means that the discharge of the pump is constant for a given speed, thus not allowing any dynamic power consumption from the grid when operated at a fixed speed. The behaviour of the Z'Mutt synchronous machine equipped with a frequency converter following a power reference change can be seen on Fig. 11. With the load torque remaining constant due to the constant head, a change of $20 \%$ in the power reference is done at the time instance $t=13 \mathrm{~s}$, and the frequency converter follows this reference within 0.12 seconds. The increase of the reference power from $80 \%$ of the nominal power to nominal power is tracked by the frequency converter within the same response time as the falling power reference, under the condition that the nominal stator current can be increased above the rated value of the machine. Compared to the inrush current during the start-up without FSFC of 4 times the rated value for 30 seconds seen on Fig. 5, and because the machine has been designed to withstand that current, this $40 \%$ above nominal current for about 10 seconds seen on Fig. 12 will not cause any damage to the machine. The three-phase stator currents and voltages are shown on Fig. 13.

Pumping above nominal speed: Pumping above rated speed of the machine is also of interest for the power plant station owners of Z'Mutt. The upper reservoir being also connected to the power plant station Bieudron, where the 


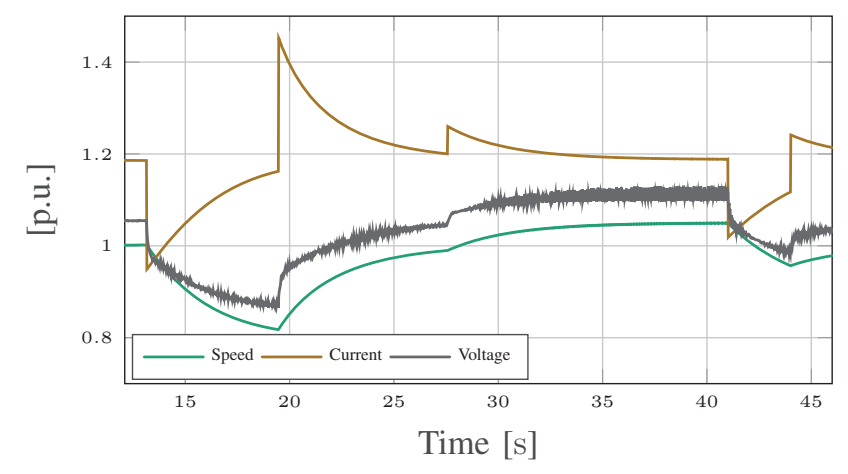

Fig. 12. Pumping simulation results showing the normalized variation of speed, stator current, stator voltage and load torque with a FSFC.

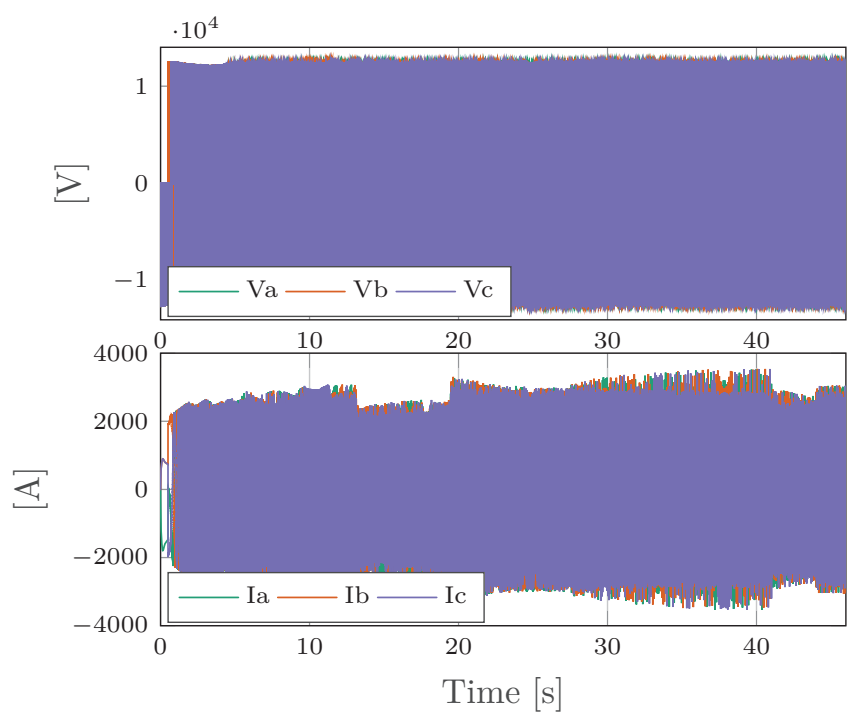

Fig. 13. Stator voltage and current from the frequency converter during pumping simulation. Stator current frequency varying with the mechanical speed of the motor, and the amplitude varies with the power reference change.

water pumped from Z'Mutt is used for generating power. However, the head of the Bieudron power plant $(1883 \mathrm{~m})$ is approximately 4 times higher than the head of U1 and U2 of the Z'Mutt power plant station, meaning that for every additional $\mathrm{kWh}$ pumped in Z'Mutt with either of the $\mathrm{U} 1$ or $\mathrm{U} 2$, an addition of $4 \mathrm{kWh}$ is gained at the power plant station of Bieudron. As the pumping speed is varying linearly with the power, increasing the pumping speed by $1 \%$ results in the same percentage increase for the power and leads to an additional $28.34 \mathrm{MW} * 0.01 * 4=1.13 \mathrm{MW}$ of production in the Bieudron power plant station due to the addition of the water in the upper reservoir. As seen on Fig. 12, the speed of the unit is exceeding the nominal speed by $5 \%$ at the time $\mathrm{t}=40 \mathrm{~s}$, and stator current and voltage remain close to nominal values, meaning that this operation region is feasible if the converter is capable of exceeding $50 \mathrm{~Hz}$ output frequency.

\section{CONCLUSION}

The fast response to a change in the grid power reference, as well as the faster start-up of the first pump unit U1 without exceeding the nominal stator current demonstrate how the installation of a FSFC increases the flexibility of the PHSP and contributes to the relevance of the power plant station on a evolving power market. The relatively low power of U1 (30MW) eliminates the main drawback of the FSFC, as commercial equipment at such power rating is currently available on the market.

\section{ACKNOWLEDGEMENTS}

The results presented in this paper are a part of the Hydropower Extending Power System Flexibility (XFLEX HYDRO) project that has received funding from the European Union's Horizon 2020 research and innovation programme under grand agreement No 857832.

\section{REFERENCES}

[1] M. Valavi and A. Nysveen, "Variable-speed operation of hydropower plants: A look at the past, present, and future," IEEE Industry Applications Magazine, vol. 24, no. 5, pp. 18-27, 2018.

[2] J. Janning and A. Schwery, "Next generation variable speed pump-storage power stations," in 2009 13th European Conference on Power Electronics and Applications, Sep. 2009, pp. 1-10.

[3] E. Nobile, G. Sari, and A. Schwery, "Variable speed hydro pumped storage as flexible enabler of intermittent renewable penetration," in 2018 IEEE Power Energy Society General Meeting (PESGM), Aug. 2018, pp. 1-5.

[4] P. K. Steimer, O. Senturk, S. Aubert, et al., "Converterfed synchronous machine for pumped hydro storage plants," in 2014 IEEE Energy Conversion Congress and Exposition (ECCE), Sep. 2014, pp. 4561-4567.

[5] H. Schlunegger and A. Thöni, "100 mw full-size converter in the grimsel 2 pumped-storage plant," Innsbruck, Hydro, 2013.

[6] M. Canay, "Asynchronous starting of a 230 mva synchronous machine in vianden-10 pumped storage station," BROWN BOVERI REVIEW, vol. 61, no. 7, pp. 313-318, 1974.

[7] S. N. Vukosavic, Electrical machines. Springer Science \& Business Media, 2012.

[8] M. Basić, P. C. O. Silva, and D. Dujić, "High Power Electronics Innovation Perspectives for Pumped Storage Power Plants," in 2018 Hydro conference, Oct. 2018.

[9] M. Vasiladiotis, R. Baumann, C. Häderli, et al., "Igctbased direct ac/ac modular multilevel converters for pumped hydro storage plants," in 2018 IEEE Energy Conversion Congress and Exposition (ECCE), 2018, pp. 4837-4844.

[10] A. Hämmerli and B. Ødegård, "Ac excitation with anpc," ABB Review, vol. 3, pp. 40-43, 2008. 